\title{
Systemic lupus erythematosus and autoimmune hepatitis
}

\author{
Cumali Efe $\cdot$ Tugrul Purnak $\cdot$ Ersan Ozaslan
}

Received: 12 April 2010 / Accepted: 14 July 2010 / Published online: 28 July 2010

(C) Springer-Verlag 2010

Liver involvement in patients with connective tissue diseases such as systemic lupus erythematosus (SLE), systemic sclerosis, Sjögren's syndrome and rheumatoid arthritis is not an uncommon condition. Hepatotoxic drugs, hepatosteatosis, coincident viral hepatitis and autoimmune hepatic diseases are main causes of liver enzymes abnormality in these patients [1]. We read with great interest the study report of Leonardo et al. regarding the coexistence of autoimmune hepatitis (AIH) and SLE [2].

Hepatic lesions due to AIH in patients with SLE are thought to be rare, but some studies showed that AIH is a common cause of liver enzymes abnormality in patients with SLE. Recently, Her et al. [3] reported 46 and Chowdhary et al. [4] 40 patients with SLE and concomitant liver enzyme abnormalities, the diagnosis of AIH was made 5 $(11 \%)$ and $6(15 \%)$, respectively.

Although SLE and AIH are different entities, they have very similar features such as female predominance, genetic susceptibility, polyarthralgia, hypergammaglobulinemia, ANA, ASMA, anti-ribonucleoprotein and ds-DNA positivity, hemolytic anemia and the good response to corticosteroid therapy $[1,5]$. Therefore, merely reliance on serologic criteria may lead to a diagnostic confusion.

Malar rash, oral ulcer, serositis, renal and cranial involvement, and hypocomplementemia are specific clinical and laboratory indicators of SLE. These findings can help to

\footnotetext{
C. Efe $(\square)$

Internal Medicine Department,

Ankara Numune Research and Education Hospital,

Yazgan sokak 21/12 Cebeci, Ankara, Turkey

e-mail: drcumi21@hotmail.com

T. Purnak · E. Ozaslan

Gastroenterology Department,

Ankara Numune Research and Education Hospital,

Cebeci, Ankara, Turkey
}

differentiate SLE from AIH [1]. The diagnosis of AIH is also difficult in patients with SLE due to clinical and laboratory similarities. International Autoimmune Hepatitis Group criteria [6] has a low sensitivity and specificity for this condition. For definitive diagnosis, specific biopsy findings are necessary periportal piecemeal necrosis associated with lobular activity, and lymphoid infiltration and rosette formation are characteristic in AIH, while in SLE, paucity of lymphoid infiltrates is observed in lobular and occasionally portal areas [1].

In conclusion, as explained earlier, the coexistence of these two entities is common. Although the diagnosis of SLE in patients with AIH could be made by specific clinical findings, the diagnosis of AIH in patients with SLE should be made based on specific biopsy findings of AIH.

\section{References}

1. Efe C, Ozaslan E, Nasiroglu N, Tunca H, Purnak T, Altiparmak E (2010) The development of autoimmune hepatitis and primary biliary cirrhosis overlap syndrome during the course of connective tissue diseases: report of three cases and review of the literature. Dig Dis Sci 55:2417-2421

2. Schiavon LL, Carvalho-Filho RJ, Narciso-Schiavon JL, Lanzoni VP, Ferraz ML, Silva AE (2012) Late-onset systemic lupus erythematosus-associated liver disease. Rheumatol Int. PMID: 20376663

3. Her M, Lee Y, Jung E, Kim T, Kim D (2009) Liver enzyme abnormalities in systemic lupus erythematosus: a focus on toxic hepatitis. Rheumatol Int. PMID: 19885660

4. Chowdhary VR, Crowson CS, Poterucha JJ, Moder KG (2008) Liver involvement in systemic lupus erythematosus: case review of 40 patients. J Rheumatol 35:2159-2164

5. Efe C, Purnak T, Ozaslan E, Wahlin S (2010) The serological profile of the autoimmune hepatitis/primary biliary cirrhosis overlap syndrome. Am J Gastroenterol 105:226

6. Alvarez F, Berg PA, Bianchi FB, Bianchi L, Burroughs AK, Cancado EL et al (1999) International Autoimmune Hepatitis Group report: review of criteria for diagnosis of autoimmune hepatitis. J Hepatol 31:929-938 